\title{
THE USE OF BOARD GAMES IN HEALTHCARE TEACHING
}

\author{
Jakub Lickiewicz ${ }^{1 \mathrm{~A}, \mathrm{D}, \mathrm{F}}$, Patricia Paulsen Hughes ${ }^{20, E, F}$, Marta Makara-Studzińska ${ }^{1 E, F}$
}

1Department of Health Psychology, Jagiellonian University Medical College, Krakow, Poland

${ }^{2}$ College of Education, Health, and Aviation, Oklahoma State University - Stillwater, United States

Authors' contribution:

A. Study design/planning • B. Data collection/entry • C. Data analysis/statistics • D. Data interpretation $\bullet$ E. Preparation of manuscript $\bullet$ F. Literature analysis/search $\bullet$ G. Funds collection

\author{
Address for correspondence: \\ Dr Jakub Lickiewicz \\ Department of Health Psychology \\ Jagiellonian University Medical College \\ 25 Kopernika St., 31-501 Krakow, Poland \\ e-mail: jlickiewicz@cm-uj.krakow.pl \\ SUBMITTED: 29.05 .2020 \\ ACCEPTED: 01.07.2020 \\ DOI: https://doi.org/10.5114/ppiel.2020.98766
}

\begin{abstract}
Modern healthcare education has occurred in an era of great challenges, but also of great opportunities. Learners have become accustomed to being bombarded by multiple stimuli to the point where traditional education often seems boring and monotonous. For this reason, modern teaching methods based on information technology are increasingly being used.

Gamification, the use of game elements in a non-entertainment context, is becoming increasingly popular in education. These include board games.

The literature on board games highlights many areas in which board games can be effective within healthcare settings. Board games differ from electronic ones primarily because of the element of social interaction, although some electronic games exist in the form of puzzles or competition with the game mechanism itself. The biggest advantages of board games include improving communication and active learning based on interaction with other players. Board games cannot substitute traditional teaching, but they can help students to master particularly difficult concepts. Games help to organise knowledge, engage and motivate students to learn difficult material, but also encourage students to take responsibility for their learning.

Games in medical education, when properly used, can be valuable tools for an instructor. They create a non-threatening environment that supports mutual learning. A properly prepared game, tailored to the subject, allows mastery of the material in less time than in a traditional lecture.
\end{abstract}

Key words: nursing, gamification, board games, health sciences, education process.

\section{INTRODUCTION}

Modern healthcare education has occurred in an era of great challenges, but also of great opportunities. Learners have become accustomed to being bombarded by multiple stimuli to the point where traditional education often seems boring and monotonous. For this reason, modern teaching methods based on information technology are increasingly being used. One example in healthcare would be the use of virtual reality (VR) in training to prevent aggressive behaviour against medical personnel [1]. Virtual reality in teaching medical staff gives great opportunities; however, it is expensive to implement.

E-learning is a more popular and cheaper way than traditional teaching to increase the attractiveness of educational activities. E-learning should be understood as a very general concept, related to computer-based learning or traditional content supported by computer technology. Most often it is identified with distance learning. E-learning is a process of acquiring knowledge, and technology facilitates it, utilising communication and visual technologies [2].
Gamification, the use of game elements in a non-entertainment context, is becoming increasingly popular in education [3]. Learning objectives can be replaced by in-game tasks for which a user receives points, experience levels, or virtual goods. An element of competition and unlocking further goals raises motivation for the learner. An important component is the freedom to choose the means of achieving the goal and reducing the risk of failure, achieved through the possibility of multiple approaches to the same task [4], also known as divergent discovery [5]. In this sense, gamification can be one of the ways to transfer knowledge, and e-learning can be a platform for its creation. There are ways to use entertainment without electronic means. These include board games. The biggest advantages of board games include improving communication and active learning based on interaction with other players [6]. Many of the modern electronic games also present an opportunity for interaction with multiple players. However, board games differ from electronic ones primarily because of the element of 
personal social interaction, although some electronic games exist in the form of puzzles or competition with the game mechanism itself. Electronic games are an interesting option in education, but it is more difficult to adapt them to medical settings than traditional board games.

\section{THE ADVANTAGES OF BOARDGAMES IN PATIENT EDUCATION}

The literature on board games highlights many areas in which they can be effective within healthcare settings in the context of patient education. French researchers showed that over a 20-year longitudinal study, board game players were $15 \%$ less likely to get dementia, and they also received higher scores on the Mini-Mental State Examination (MMSE) and lower scores on the depression scale [7]. Board games require planning and logical thinking, keeping those areas of the brain active. The effectiveness of games with patients with Alzheimer's disease has also been shown, especially in the area of depression and anxiety symptoms co-occurring [8]. An additional protective element is the aforementioned social interaction because players have a better chance of socialising, which creates social bonds and prevents premature ageing [9].

Board games also have a positive effect on physical activity and ADHD symptoms. The therapeutic intervention by Mouton et al. [10] of a large board game in a nursing home led to a significant increase in physical activity, energy level, quality of life, and balance and strength in the group of participants. A meta-analysis also showed a significantly high impact of board games on ADHD symptoms in children. They can also be useful in the therapeutic process of people with poorly developed or impaired speech ability, e.g. in aphasia [9].

Board games also provide a means of coping with stress by being able to discharge negative emotional states [11]. Studies on a group of people with depression and anxiety showed a decrease in symptoms after six weeks of a stress management program in which the board game Shogi was used [12]. In this case, the board game was not a separate intervention but was part of a more comprehensive therapeutic program. Board games also play an important role during times of quarantine, such as the recent COVID-19 pandemic (personal experience).

Board games can also change habits and promote healthy behaviours. In a Swiss study, smokers used an educational board game as part of therapy. After the therapy, people in the experimental group less often returned to addiction than those from the control group [13].

The aim of the study is to present the effectiveness of the boardgames in health care education.

\section{APPLICATIONS IN MEDICAL EDUCATION}

Game-based learning (GBL) in medical education is defined as an alternative to traditional teaching [14]. There are two ways of using board games in medical education, either by using existing games or by creating new ones tailored to a specific topic. In the first case, the element of acquiring knowledge is omitted, because these are games that most often serve as entertainment. However, GBL could be used as a way to integrate a workgroup or to master so-called "soft competencies", such as interpersonal communication or teamwork. One advantage is universality, but game-based learning will not allow one to master the knowledge of the topic being taught during the education process. For this reason, new board games are created or existing ones are modified to better fulfil the educational task $[6,9]$.

Board games are used in academia, especially for medical and healthcare students. They have many advantages in this area of education:

- they can teach complex issues without risking a live patient or needing expensive equipment,

- participants can exercise or practice without suffering the negative consequences of incorrect medical decisions,

- games bring an element of pleasure, reduce anxiety, and distract users from stressful clinical situations,

- players are active in the learning process,

- teamwork and team building - participants share their knowledge and engage in teaching each other. As the research on medical residents shows, learning from each other is an effective [5] and important way of acquiring knowledge [15].

- the ability of boardgames to combine theory and practice [16].

Bochenek et al. [6] proposed a typology of games used in medical education depending on the player's level of involvement:

- one-stage, simple games consisting of a single stage,

- two stages, containing the possibility of reflecting and summarising the activity,

- three stages, containing previous ones enriched with active planning,

- four stages, when the game mechanism creates the three previously mentioned elements.

Also, games can be categorised by type (dice and luck, outlay games, thinking games, quiz/communication games, role-play and simulations, dexterity games). This classification shows the greater complexity of the issue and is also intended to facilitate the selection of appropriate mechanisms for educational purpose.

The most popular in education, because they are the easiest to adapt, are quiz games in which students are asked to answer questions about general knowledge in medicine. In Beylefeld and Stuwig's [17] study, 
students played a board game as part of a course in microbiology. It was a one-stage game. The game had seven colour-coded categories from which to choose. Correct answers were rewarded with tokens. When they evaluated the game, students pointed out that they paid more attention to learning, began synthesising the material, and used their textbooks more often.

In another study, students in an anatomy course learned course material through a card game in which they were given assignments to compare venous drainage of intestinal organs in a healthy patient compared to one with hypertension. Students noted that they enjoyed playing the game, and also did better on the exam than those who had not played the game [18].

In the Graham and Richardson study [19], a threestage communication game was used during a course to foster cultural knowledge and skills. Nursing students played a card game at several different tables, each with different rules. After the course, students reported they had learned how to improve their intercultural relations.

Some games are more complex, e.g. students develop a plan for dealing with patients in the Emergency room. The task of this three-stage thinking game is to decide on appropriate treatment based on the medical documentation received. The whole process is supervised and directed by the teacher, and students' decisions can be modified [6].

Role-playing and simulation are two more types of games that were used in Fukuchi's study [20]. The research challenge was to heal a simulated oncological patient. The students moved the patient between hospital departments, ordering diagnostics and treatment. Movement of the patient was directed by the correct answers to questions and the dice roll. The process was supported by a computer that provided students with medical information about their patients. Students noted the increase in their knowledge in the area of oncology after playing the game.

Board games can also help to enhance specialised knowledge. The boardgame Criticality, based on the popular Monopoly game, was a part of the learning process at an intensive care unit in Northumbria, UK. It allowed nursing students to learn about gaps in knowledge, to get feedback, to learn a specific way to respond, and to integrate knowledge from a given module. According to the authors, Criticality was a new strategy that improved the quality of teaching [16]. Because of the use of medical language, often patients and family do not understand what they are being told by medical personnel. In Jargonbe-gone, adapted from the popular Taboo game, students were given negative points for using colloquial words or medical jargon that the patient might not understand [14].
Board games in education, despite their advantages, arouse some controversy. Opponents ask to what extent the process of teaching serious subject matter should be turned into a "playground". There is a danger that board games can infantilise the learning process. This can be harmful and may cause learners to downplay learning by treating it as entertainment.

Another challenge that Gorbanev [21] draws attention to is the issue of testing the effectiveness of games in education. The process of learning or changing habits is so complex that the relationship between positive effects obtained is not always clearly associated with board games. Future research in this field requires a good methodological structure based on randomised trials [9].

The above explained researches based mainly on a quasi-experimental study of the two or one group with pre- and post-comparative test. Without randomised trials, it is difficult to draw conclusions unequivocally about the effectiveness of board games. It would also be beneficial to measure the Polish student's perception of this type of educational tool.

Some authors point to negative consequences of using board games in education. These include potential feelings of anxiety and embarrassment in the presence of other students because of a lack of knowledge or skills. Creating games requires time and energy, and it engages the instructor more than is the case with traditional teaching. The most serious objection is that board games may not be effective in assessing individual knowledge. Playing games allows active students to engage, while quieter and less assertive students may withdraw from the process [16].

To create a safe learning environment, the instructor must provide a sense of security and promote cooperation over competition. One effective method to reduce anxiety is to use questions with multiple correct answers. Some suggest changing existing games and adapting them to new conditions instead of creating new games. To maintain a balance between entertainment and learning, it is crucial to clearly define the goals a teacher wants to achieve. The effectiveness of games also depends on the number of people playing. This variable can be modified by changing the difficulty level. Groups should be small enough for everyone to have multiple turns. An important element is the assessment of the effectiveness of the games used, in as formalised a way as possible [14]. Game playing can earn validity in several ways: studies with experimental and control groups, pre- and post-testing, formal evaluation, and isolating game playing effects from other potential confounders.

Board games cannot substitute traditional teaching, but they can help students to master particularly difficult concepts. Games help to organise knowledge, engage and motivate students to learn difficult 
material, but also encourage students to take responsibility for their learning [22, 23].

Games in medical education, when properly used, can be valuable tools for an instructor. They create a non-threatening environment that supports mutual learning. A properly prepared game, tailored to the subject, allows mastery of the material in less time than in a traditional lecture [14]. However, future studies should support the validity and emphasise the proper methodology of this practice. Thanks to games, the lecturer ceases to be a talking head and becomes a facilitator for acquiring knowledge, who also has the ability to continually assess students' work and modify as necessary [14]. Students, thanks to the games approach, learn through experience, not rote memorisation.

\section{Disclosure}

The authors declare no conflict of interest.

\section{References}

1. Tuente SK, Bogaerts S, Van ljzendoorn S, et al. Effect of virtual reality aggression prevention training for forensic psychiatric patients (VRAPT): study protocol of a multi-center. RCT. BMC Psychiatry 2018; 18: 1-9.

2. Aparicio M, Bacao, F, Oliveira T. An e-learning theoretical framework. An e-learning theoretical framework. JSTOR 2016; 1: 292-307.

3. Domínguez A, Saenz-De-Navarrete J, De-Marcos L, et al. Gamifying learning experiences: Practical implications and outcomes. Computers \& Education 2013; 63: 380-392.

4. Dicheva D, Dichev C, Agre G, et al. Gamification in education: A systematic mapping study. J Educ Technol Soc 2015; 18: 1-14.

5. Mosston M, Ashworth S. The spectrum of teaching styles: From command to discovery. Addison-Wesley Longman Ltd, Boston 1989.

6. Bochennek K, Wittekindt B, Zimmermann SY, et al. More than mere games: a review of card and board games for medical education. Med Teach 2007; 29: 941-948.

7. Akbaraly TN, Portet F, Fustinoni S, et al. Leisure activities and the risk of dementia in the elderly: results from the ThreeCity Study. Neurology 2009; 73: 854-861.

8. Lin Q, Cao Y, Gao J. The impacts of a GO-game (Chinese chess) intervention on Alzheimer disease in a Northeast Chinese population. Front Aging Neurosci 2015; 7: 163.

9. Noda S, Shirotsuki K, Nakao M. The effectiveness of intervention with board games: a systematic review. Biopsychosoc Med 2019; 13: 22.

10. Mouton A, Gillet N, Mouton F, et al. Effects of a giant exercising board game intervention on ambulatory physical activity among nursing home residents: a preliminary study. Clin Interv Aging 2017; 12: 847-858.

11. Nakao M. Special series on "effects of board games on health education and promotion" board games as a promising tool for health promotion: a review of recent literature. Biopsychosoc Med 2019; 13: 5.

12. Nakao M, Furukawa H, Oomine A, et al. Introduction of "Shogi" health promotion project in Kakogawa City. In Tokyo: 2017; Abstract of the 24th annual scientific conference of the Japanese Society of Behavioral Medicine.
13. Khazaal Y, Chatton A, Prezzemolo R, et al. Impact of a boardgame approach on current smokers: a randomized controlled trial. Subst Abuse Treat Prev Policy 2013; 8: 3.

14. Pitt MB, Borman-Shoap EC, Eppich WJ. Twelve tips for maximizing the effectiveness of game-based learning. Med Teach 2015; 37: 1013-1017.

15. Thampy H, Agius S, Allery L. Clinical teaching: widening the definition. Clin Teach 2014; 11: 198-202.

16. Gibson V, Douglas M. Criticality: The experience of developing an interactive educational tool based on board games. Nurse Educ Today 2013; 33: 1612-1616.

17. Beylefeld AA, Struwig MC. A gaming approach to learning medical microbiology: students' experiences of flow. Med Teach 2007; 29: 933-940.

18. Hill RV, Nassrallah Z. A game-based approach to teaching and learning anatomy of the liver and portal venous system. MedEdPORTAL 2018; 14: 10696.

19. Graham I, Richardson E. Experiential gaming to facilitate cultural awareness: its implication for developing emotional caring in nursing. Learn Health Soc Care 2008; 7: 37-45.

20. Fukuchi SG, Offutt LA, Sacks J, et al. Teaching a multidisciplinary approach to cancer treatment during surgical clerkship via an interactive board game. Am J Surg 2000; 179: 337-340.

21. Gorbanev I, Agudelo-Londoño S, González RA, et al. A systematic review of serious games in medical education: quality of evidence and pedagogical strategy. Med Educ Online 2018; 23: 1438718.

22. Abdulmajed H, Park YS, Tekian A. Assessment of educational games for health professions: a systematic review of trends and outcomes. Med Teach 2015; 37 (suppl. 1): S27-S32.

23. Gauthier A, Kato PM, Bul KC, et al. Board games for health: A systematic literature review and meta-analysis. Games Health J 2019; 8: 85-100. 